\title{
LA DESCONEXIÓN DIGITAL COMO LÍMITE FRENTE A LA INVASIÓN DE LA PRIVACIDAD
}

\author{
Nuria Reche Tello \\ Graduada Social. Profesora Asociada Doctora \\ Área de Derecho Constitucional \\ Universidad Miguel Hernández de Elche
}

\begin{abstract}
La Ley Orgánica de Protección de Datos de Carácter Personal y Garantía de los Derechos Digitales introduce en nuestro ordenamiento el derecho a la desconexión digital. Del análisis de sus antecedentes normativos y jurisprudenciales, así como de su configuración legal y contenido, se desprende su naturaleza fundamental en conexión con derechos como la privacidad, la conciliación de la vida personal y laboral, o la protección de la salud de los trabajadores. Ello desde su vertiente de derecho de libertad o autonomía, es decir, como un límite frente al poder de dirección de la empresa o, si se quiere, como el deber empresarial de no interferir en la vida personal de los trabajadores fuera de su jornada laboral, pero también con una faceta prestacional o de obligación de hacer, en el sentido del deber empresarial de velar por la prevención y vigilancia de la salud de los trabajadores.
\end{abstract}

The Organic Law of Personal Data Protection and Digital Rights Guarantee introduces in our legal system the right to digital disconnection. From the analysis of its normative and jurisprudential antecedents, as well as its legal configuration and content, it follows its fundamental nature in connection with rights such as privacy, work-life balance, or protection of the workers' health. All this from its standpoint of freedom or autonomy right, that is, as a limit to the corporate management power or, if you like, as a business duty not to interfere with personal life of workers outside their working day, but also with a prestacional facet or obligation to make, in the sense of a business duty to ensure the prevention and vigilance of the workers' health

IUSLabor 3/2019, ISSN 1699-2938, p. 31-54

DOI. 10.31009/IUSLabor.2019.i03.02

Fecha envío: 30.1.2019 | Fecha aceptación: 6.3.2019

Title: The digital disconnection as a limit against the invasion of privacy 
Palabras clave: derecho a la desconexión digital, conciliación de la vida personal y laboral, intimidad, salud, límites, deberes, poder de dirección empresarial Key words: the right to disconnect digitally, work-life balance, privacy, health, limits, duties, corporate management power

\section{Sumario}

1. Introducción

2. Ámbito normativo y jurisprudencial del derecho a la desconexión digital

2.1. Tiempo de trabajo y descanso en el ámbito internacional y europeo

2.2. La normativa estatal: de la Constitución a la Ley Orgánica de Protección de Datos y Garantía de los Derechos Digitales

2.3 Experiencias en la negociación colectiva

2.4 Apuntes jurisprudenciales en materia de descanso

3. Naturaleza y contenido del derecho a la desconexión digital

4. Conclusiones

5. Bibliografía 


\section{Introducción}

El uso exponencial de las nuevas tecnologías ha propiciado en los últimos tiempos que la frontera que separa el tiempo de trabajo y la vida personal se difumine, de manera que, por una parte, la flexibilidad que otorgan estas herramientas permiten a los trabajadores una mayor facilidad para conciliar vida personal y laboral pero, al mismo tiempo, en numerosas ocasiones, estos se ven obligados a estar disponibles durante un mayor número de horas y atender a los requerimientos laborales en todo momento y lugar, lo que puede ocasionar ciertas intromisiones en su intimidad, además de la exposición a nuevos riesgos psicosociales derivados del tecno-estrés o la tecnoadicción. Así se afirma en el informe de la OIT-Eurofound: Working anytime, anywhere: The effects on the world of work $^{1}$, donde se destaca la necesidad de desconectarse para separar el trabajo de la vida personal, así como de abordar la regulación del teletrabajo. En este sentido, el denominado "Informe Mettling"2 supuso un antecedente de las primeras regulaciones del derecho a la desconexión digital. En él se recogen determinadas experiencias sobre duración del tiempo de trabajo que favorecen la desconexión, tanto en acuerdos sectoriales como en algunas empresas. Este informe fue el punto de partida para la elaboración de la previsión legal francesa, la denominada Ley "El Khomri" o Loi Travail 2016-1088, de 18 de agosto de 2016³ y que entró en vigor el pasado 1 de enero de 2017, donde se incorpora la desconexión digital como un derecho para los trabajadores -y una correspondiente obligación para las empresas- con el fin de regular el uso de las tecnologías de la comunicación y la información y así garantizar el tiempo de descanso, las vacaciones, la vida personal y familiar y la salud de los trabajadores/as, ya que, como reconoce la propia norma, si las tecnologías están mal controladas pueden tener un impacto negativo sobre estas cuestiones. La ley francesa, que opta por remitir a la negociación colectiva su desarrollo

\footnotetext{
${ }^{1}$ Disponible en: https://www.eurofound.europa.eu/publications/report/2017/working-anytime-anywherethe-effects-on-the-world-of-work. Consultado 28 de diciembre de 2017.

${ }^{2}$ Informe que con el nombre "Transformation numérique et vie au travail", fue elaborado por el Sr. Bruno Mettling, a petición de la Ministra de Trabajo, Empleo y Formación Profesional y Dialogo Social, Sra. Mme Myriam El Khomri, en septiembre de 2015.

${ }^{3}$ El artículo 55.I.2.o L 2016-1088 introduce un nuevo apartado 7 en el artículo L 2242-8 del Código de Trabajo francés disponiendo que la negociación anual sobre igualdad profesional entre las mujeres y los hombres y la calidad de vida en el trabajo incluirá: " $7^{\circ}$ Las modalidades del pleno ejercicio por el trabajador de su derecho a la desconexión y la puesta en marcha por la empresa de dispositivos de regulación de la utilización de los dispositivos digitales, a fin de asegurar el respeto del tiempo de descanso y de vacaciones, así como de su vida personal y familiar. A falta de acuerdo, el empleador, previa audiencia del comité de empresa o, en su defecto, de los delegados de personal, elaborará una política de actuación al respecto. Esta política definirá las modalidades de ejercicio del derecho a la desconexión y preverá, además, la puesta en marcha de acciones de formación y de sensibilización sobre un uso razonable de los dispositivos digitales, dirigida a los trabajadores, mandos intermedios y dirección".
} 
en aquellas empresas de más de 50 trabajadores, lo asocia con a la igualdad de mujeres y hombres y la calidad de vida en el trabajo, debiendo la empresa, a falta de acuerdo, y previa audiencia con los representantes de los trabajadores, elaborar una política de actuación en la que se definan los aspectos de este derecho.

En nuestro país, la Ley Orgánica de Protección de Datos y Garantía de los Derechos Digitales 3/2018 de 5 de diciembre, publicada en el BOE el 6 de diciembre, en adelante LOPDyGDD, introduce en su Título X denominado "Garantía de los derechos digitales", entre otros, el derecho a la desconexión digital en el ámbito laboral, a fin de asegurar fuera del tiempo de trabajo el respeto al descanso y la intimidad, definiéndose como un elemento potenciador de la conciliación de la vida personal y laboral. Un análisis, en primer lugar, de sus antecedentes normativos y jurisprudenciales, para, a continuación, abordar su posible naturaleza y contenido, nos ofrecerá algunas respuestas sobre este nuevo derecho/deber en la era de las comunicaciones digitales.

\section{2. Ámbito normativo y jurisprudencial del derecho a la desconexión digital}

Los primeros antecedentes debemos situarlos en el reconocimiento del clásico derecho al descanso de principios del siglo XX, y es que la desconexión digital no deja de ser la reinterpretación de una de las primeras reivindicaciones laborales, que en su evolución conecta con un derecho fundamental propio de los nuevos tiempos, el derecho a conciliar la vida personal y familiar con la vida profesional, todo ello como expresión de la primacía de los derechos fundamentales inespecíficos que se ejercen en la relación laboral, y que nuestra Constitución y los Tratados Internacionales garantizan.

\subsection{Tiempo de trabajo y descanso en el ámbito internacional y europeo}

El primer convenio acordado en el seno de la OIT, el Convenio $\mathrm{n}^{\mathrm{o}} 1$ sobre las horas de trabajo (industria), firmado en 1919, aborda el derecho al descanso con el propósito de limitar las horas de trabajo en las empresas industriales a ocho diarias y cuarenta y ocho semanales. Más tarde, la Declaración Universal de Derechos Humanos de Naciones Unidas de 1948, en adelante DUDH, reconoce en su artículo 24 un derecho "que tiene que ver con una de las cuestiones más de moda en el siglo XXI en el ámbito de las relaciones laborales: el derecho a la limitación del tiempo de trabajo para facilitar el descanso del trabajador y la posibilidad de disposición de tiempo libre para disfrutar

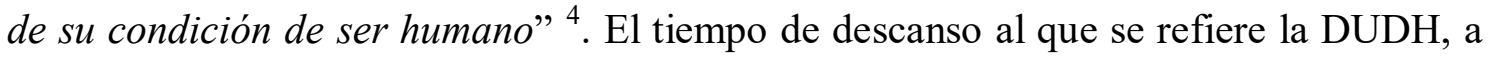
su vez directamente relacionado con la necesidad de garantizar la seguridad y salud en

\footnotetext{
${ }^{4}$ Sempere Navarro, A. V. Y Cano Galán, Y., «La igualdad laboral en la Declaración Universal de Derechos Humanos», Revista Europea de Derechos Fundamentales, n. ${ }^{\circ} 11$ (1er semestre de 2008): pp.67136.
} 
el trabajo, se manifiesta, por una parte, en la limitación de la jornada para permitir que los individuos puedan satisfacer sus necesidades vitales, esto es, el tiempo libre; y por otra, en la concesión de tiempo adicional de descanso para posibilitar que los sujetos se recuperen tras los periodos de actividad prolongada, y que se hace coincidir con el término "vacaciones". Sin embargo, "presumiblemente la concepción de los redactores de la DUDH va más allá, vinculando dicho tiempo adicional de descanso a una finalidad en concreto: la posibilidad de desarrollo social del individuo", una concepción amplia que tiene que ver "con la necesidad de que el trabajador disponga de tiempo de ocio o que pueda destinar a aspectos de su vida privada y de sociabilidad con otros individuos" 5. A su vez, el Pacto Internacional de Derechos Económicos, Sociales y Culturales, adoptado y abierto a la firma, ratificación y adhesión por la Asamblea General en su resolución 2200 A (XXI), d|e 16 de diciembre de 1966, recoge en su artículo 7 que los Estados Parte reconocen el derecho de toda persona al goce de condiciones de trabajo equitativas y satisfactorias que le aseguren, en especial, entre otros: el descanso, el disfrute del tiempo libre, la limitación razonable de las horas de trabajo y las vacaciones periódicas pagadas, así como la remuneración de los días festivos. Del mismo modo, la Carta Social Europea de 1966 en su artículo 2 recoge el derecho a unas condiciones de trabajo equitativas, en términos similares.

Más concretamente, en el marco de la UE, la Directiva 2003/88/CE del Parlamento Europeo y del Consejo, de 4 de noviembre de 2003, regula determinados aspectos de la ordenación del tiempo de trabajo, siendo de aplicación a todos los sectores de actividad, privados y públicos. En ella se define el concepto de tiempo de trabajo en su artículo 2.1 como "todo el periodo durante el cual el trabajador permanezca en el trabajo, a disposición del empresario y en el ejercicio de su actividad o sus funciones". De manera negativa, el tiempo de descanso se expresa en su artículo 2.2 como "todo periodo que no sea tiempo de trabajo". La Directiva, en sus artículos 3 a 6 impone a los Estados miembros que adopten las medidas para asegurarse de que el trabajador disponga de un descanso adecuado y efectivo. Y es que el derecho de la UE impone que los conceptos de tiempo de trabajo, descanso, tiempo de presencia y trabajo efectivo se interpreten de manera uniforme en todo el ámbito comunitario para garantizar eficazmente la aplicación de la normativa y la seguridad y salud de los trabajadores. Así, por ejemplo, el tiempo de disponibilidad tecnológica habrá de ser considerado tiempo de trabajo, con independencia del lugar en que se preste, tal y como ha afirmado la Sentencia del Tribunal de Justicia de la Unión Europea, en delante STJUE, de 21 de febrero de 2018, C-518/15, asunto Matzak, que no permite a los Estados miembros mantener o adoptar una definición del concepto de tiempo de trabajo menos restrictiva que la que contiene

\footnotetext{
${ }^{5}$ Sempere Navarro, A. V. Y CANo Galán, Y.
} 
el artículo 2 de la Directiva ${ }^{6}$. Por su parte, la Directiva 93/104 establece las disposiciones mínimas de seguridad y salud en materia de ordenación de la jornada laboral, teniendo por objeto mejorar las condiciones de vida y de trabajo mediante la aproximación de las normas nacionales relativas, en concreto, a la duración del tiempo de trabajo. Concretamente los artículos 3 y 5 regulan los periodos mínimos de descanso diario y semanal. Esta armonización a nivel comunitario en materia de ordenación del tiempo de trabajo garantiza así una mejor protección de la seguridad y de la salud, haciendo que los trabajadores disfruten de períodos mínimos de descanso -diario y semanal-, así como de pausas adecuadas y estableciendo un límite máximo de cuarenta y ocho horas para la duración media de la semana de trabajo, límite que incluye las horas extraordinarias.

\subsection{La normativa estatal: de la Constitución a la Ley Orgánica de Protección de Datos y Garantía de los Derechos Digitales}

Nuestra Constitución reconoce el derecho al descanso en el artículo 40.2, dentro del Capítulo III del Título I, dedicado a los principios rectores de la política social y económica. Este derecho, como decíamos, está directamente vinculado con una de las conquistas más importantes de las reivindicaciones obreras, la limitación de la jornada laboral. En su dimensión constitucional hay que interpretarlo en el sentido de asegurar que se ponen en marcha medidas para lograr el descanso de los trabajadores que, a su vez, repercutan en la mejora de su calidad de vida. Por ello, el precepto hace referencia a la limitación de la jornada laboral y a las vacaciones periódicas retribuidas. Además, el derecho al descanso no puede entenderse sin su conexión con los derechos fundamentales de la personalidad y que nuestra Constitución contempla: los derechos de intimidad personal (18.1), secreto de las comunicaciones (18.3) y protección de datos de carácter personal (18.4). Como explica Casas Bahamonde ${ }^{7}$ el Tribunal Constitucional en su temprana STC 110/1984 "procedió a equiparar el derecho a la intimidad con el derecho a la vida privada para extender su ámbito de protección global más allá del domicilio y garantizar un ámbito reservado de la vida de las personas frente a la acción y conocimiento de terceros, sean poderes públicos o particulares 'necesario, según las pautas de nuestra cultura, para mantener una calidad mínima de la vida humana'. Decisiones posteriores llevarían ese ámbito reservado de la vida, la 'propia esfera de desenvolvimiento del individuo' a las relaciones laborales, ligándolo a la dignidad humana y destacando que el atributo más importante del derecho a la intimidad, como núcleo central de la personalidad, es la facultad de exclusión de los demás, de

\footnotetext{
${ }^{6}$ Moreno GonZalez-AlLeR, I., «El derecho de los trabajadores a la desconexión tecnológica», Revista Jurisprudencia El Derecho 2 (2018).

${ }^{7}$ CASAS Bahamonde, M. E., "Anotaciones sobre las obligaciones del Estado de garantizar la vida privada en el trabajo en la era digital», Actum Social 136 (junio de 2018).
} 
abstención de injerencias por parte de otro, tanto en lo que se refiere a la toma de conocimientos intrusiva, como a la divulgación ilegítima de esos datos".

En cuanto a su desarrollo legal, éste se efectúa en el Real Decreto Legislativo 2/2015, de 23 de octubre, por el que se aprueba el texto refundido de la Ley del Estatuto de los Trabajadores, en adelante ET, que, en sus artículos 34, 37 y 38, se encarga de regular el descanso diario, el semanal, los permisos, así como el derecho a vacaciones anuales de los trabajadores.

Cabe preguntarse si a la vista de la normativa expuesta resultaría necesario, al igual que se está haciendo en otros países ${ }^{8}$, regular un específico derecho a la desconexión digital, cuestión que ya se ha suscitado entre la doctrina científica ${ }^{9}$. A primera vista podría parecer redundante, dado que el trabajador carece, al menos formalmente, de obligaciones laborales fuera de su jornada de trabajo, y por tanto no existiría deber legal de responder, ya la empresa no tiene potestad para ordenar. Pero lo cierto es que, en la práctica, el uso de las nuevas tecnologías está propiciando muchas situaciones en las que, por ejemplo, la empresa, o sus clientes, sin emitir instrucciones precisas, se comunican o envían mensajes fuera del horario de trabajo con los trabajadores, situaciones que obviamente podrían repercutir negativamente en su vida personal y su salud. Precisamente por eso son cada vez más los autores que consideran conveniente regular legal o convencionalmente este derecho "con la simple finalidad de concienciar sobre una práctica empresarial que se encuentra ampliamente asentada" ${ }^{10}$, facilitando el descanso y evitando con ello riesgos psicosociales como el tecno-estrés, y sobre todo, garantizando la conciliación de la vida personal y laboral ${ }^{11}$. Además, sería bueno para trabajadores y empresas, "ya que si las reglas del juego están claras todo funciona

\footnotetext{
${ }^{8}$ En el caso de Francia, el derecho se reconoce en la Ley $n^{\circ}$ 2016-1088 de 8 de agosto de 2016, relativa a trabajo, a la modernización del dialogo social y al aseguramiento de las carreras profesionales, y en Italia se contempla también en la Ley de 22 mayo de 2017 no 81 de Medidas para la protección del autoempleo y para promover la articulación flexible en el tiempo y lugar del empleo subordinado. Fuera de la Union Europea otros países como Japón, Corea del Sur o Filipinas están promoviendo medidas de este tipo.

${ }^{9}$ Entre otros Vallecillo Gámez, $\mathrm{M}^{\mathrm{A}} \mathrm{R}$., «El derecho a la desconexión: "novedad digital" o esnobismo del "viejo" derecho al descanso», RTSS.CEF, n. ${ }^{\circ} 408$ (2017) o Molina NAVARRETE, C., «El tiempo de los derechos en un mundo digital: ¿Existe un nuevo "derecho humano a la desconexión" de los trabajadores fuera de la jornada?», Revista de la Facultad de Derecho de México 269, n. ${ }^{\circ}$ Tomo LXVII (2017).

${ }^{10}$ TALÉNS VISCONTI, E., «La desconexión digital en el ámbito laboral: un deber empresarial y una nueva oportunidad de cambio para la negociación colectiva», Revista de Información Laboral, n. ${ }^{\circ} 4$ (2018).

${ }^{11}$ TASCÓN LÓPEZ, R., «El derecho de desconexión del trabajador (potencialidades en el ordenamiento español) (1)», Trabajo y Derecho Sección Estudios, n. ${ }^{\circ} 41$ (2018).
} 
mucho mejor" ${ }^{\prime 2}$. Se precisa por tanto actualizar el marco de relaciones laborales a las nuevas tecnologías para garantizar el tiempo de descanso de los trabajadores adaptando "el vetusto derecho de descanso a la nueva realidad" 13 . Por otro lado, y en lo que respecta al ejercicio de los derechos de los trabajadores a un mínimo de vida privada y a la intimidad de la correspondencia en los lugares de trabajo, el ET se muestra insuficiente, ya que no regula la protección de los derechos a la privacidad en el trabajo, resultando necesaria la intervención del legislador para protegerlos "en un entorno tecnológico que puede comprometer decisivamente su efectividad, y establecer limitaciones pertinentes para asegurar su adecuada relación de proporcionalidad con los intereses generales" 14.

Así pues, a primera vista, parece conveniente y necesario sentar algunas bases para que las partes implicadas tengan claros los límites en un escenario laboral dominado por el uso, y abuso, de las nuevas tecnologías. En este contexto se aprobó el pasado diciembre la LOPDyGDD que adapta a nuestro ordenamiento jurídico el Reglamento UE 2016/679 del Parlamento Europeo y el Consejo, de 27, de abril de 2016, relativo a la protección de las personas físicas en lo que respecta al tratamiento de datos personales y a la libre circulación de los mismos, y por el que se deroga la Directiva 95/46/CE, en vigor desde el 25 de mayo de 2018. El texto legal aborda en su Exposición de Motivos la necesidad de reconocer y garantizar un elenco de derechos digitales conforme al mandato constitucional, incorporando un nuevo Título $\mathrm{X}$ denominado "Garantía de los derechos digitales" en el que, entre otros, se reconoce el derecho a la desconexión en el marco de la intimidad en el uso de dispositivos digitales en el ámbito laboral. En el apartado tercero analizaremos su contenido, naturaleza y eficacia, a fin de arrojar alguna luz en el que podemos considerar como una nueva faceta o evolución del clásico derecho al descanso en el siglo XXI.

\subsection{Experiencias en la negociación colectiva}

Como decíamos al comienzo, algunas grandes empresas, principalmente alemanas y francesas, han sido el punto de arranque en el proceso de positivación del derecho a la desconexión digital, incorporándose en los últimos años ciertas multinacionales que han introducido una serie de medidas en sus convenios colectivos con el objetivo de

\footnotetext{
${ }^{12}$ VIROLÉS PIÑOL, R, «Nuevas tecnologías aplicadas a las relaciones laborales. Incidencia de las recientes sentencias del Tribunal de Justicia de la Unión Europea y del Tribunal Europeo de Derechos Humanos sobre videovigilancia y uso de medios informáticos» (XV Jornadas Laborales, Zaragoza, 2018).

${ }^{13}$ Gordo Gonzalez, L., «El Derecho del Trabajo 2.0: la necesidad de actualizar el marco de las relaciones laborales a las nuevas tecnologías», Revista de Información Laboral 12 (2017).

${ }^{14}$ CASAS Bahamonde, M. E., «Anotaciones sobre las obligaciones del Estado de garantizar la vida privada en el trabajo en la era digital».
} 
favorecerla. MELLA MÉNDEZ ${ }^{15}$ ha estudiado el contenido de los principales acuerdos colectivos adoptados en materia de desconexión digital en estos países, extrayendo algunos datos interesantes acerca del contenido y las medidas específicas adoptadas. Así, en cuanto al ámbito subjetivo destaca que la mayoría de los acuerdos suelen ser prudentes, reconociendo el derecho sólo a los trabajadores ordinarios, y excluyendo a los de alto nivel con poderes y autonomía y con un mayor grado de responsabilidad en la empresa. Del mismo modo, estos acuerdos específicos carecen de carácter vinculante para las partes, actuando a modo de recomendaciones, lo que refleja la voluntad de introducir las medidas de desconexión tecnológica lentamente. En cuanto a su contenido general, suelen establecer una declaración general de derechos, especialmente para el trabajador, y después, en algunos casos, se precisan ciertas medidas para intentar garantizar su efectividad, siendo éstos los más interesantes precisamente por su nivel de eficacia. Entre las medidas que se dirigen a los trabajadores, se recoge el reconocimiento del derecho/deber a la desconexión, y que conlleva la obligación del trabajador de desconectarse de las herramientas de comunicación a distancia ${ }^{16}$, así como las distintas posibilidades de información, comunicación y advertencia por parte del trabajador a la empresa para la búsqueda en común de una solución que le permita los descansos mínimos. Desde el plano empresarial se enumeran las siguientes: exigencia de ejercer su poder directivo y de control para asegurar el adecuado cumplimiento de la jornada laboral máxima por parte del trabajador, así como de la correcta actuación de los directivos en la materia; adopción de medidas preventivas que impliquen audiencias al trabajador, con sensibilización y formación específica en relación con el correcto manejo de los instrumentos digitales usados como herramientas de trabajo; adopción de medidas excepcionales en casos excepcionales; e información adecuada a los órganos responsables en materia preventiva sobre los riesgos laborales que detecte en el uso de las herramientas digitales.

De manera práctica, enumeramos a continuación algunas de estas experiencias con la finalidad de conocer como se expresan las diferentes modalidades de ejercicio del derecho y valorar su nivel de eficacia.

\footnotetext{
${ }^{15}$ Mella MÉnDeZ, L., «Nuevas tecnologías y nuevos retos para la conciliación y la salud de los trabajadores (1)», Trabajo y derecho: nueva revista de actualidad y relaciones laborales 16 (2016): pp.30-52.

${ }^{16}$ Enumerando medidas tales como la supresión del aviso sonoro de llegada de un correo o mensaje, el apagado o bloqueo técnico de las funciones o aplicaciones relacionadas con el trabajo instaladas en el dispositivo o el aviso automático de que el receptor o destinatario de aquel está fuera de su puesto de trabajo.
} 
- Volkswagen: desde 2011 la empresa tiene implantado un sistema que desconecta sus servidores de comunicación de los teléfonos móviles profesionales de sus empleados entre las 18.15 horas y las 7 de la mañana del día siguiente ${ }^{17}$.

- Acuerdo colectivo de carácter sectorial celebrado entre las patronales Syntec y Cinov y los sindicatos CFDT y CFE-CGC: firmado en Francia en 2014, en él se establece el derecho y la obligación de los trabajadores de desconectarse de las herramientas de comunicación a distancia, alcanzándose acuerdos similares en otros sectores de actividad $^{18}$.

- Mercedes-Benz: la empresa, desde 2016, ofrece a sus trabajadores acogerse al sistema mail on holiday, por medio del cual los correos enviados a trabajadores que se encuentran de vacaciones son automáticamente redirigidos a otros contactos disponibles dentro de la empresa, evitando así que lleguen a sus destinatarios durante las fechas en que se encuentran de vacaciones, así como la sobrecarga de mensajes que suele seguir a tales períodos ${ }^{19}$.

- Orange: en 2016 la empresa llegó a un acuerdo con los trabajadores para establecer tiempos de no utilización de su mensajería electrónica, en particular, durante las reuniones para facilitar la concentración ${ }^{20}$.

- Michelin: limita las conexiones de los directivos que viajan entre las 9 de la noche y las 7 de la mañana, y durante todo el fin de semana. En 2016 la empresa establece un control de las conexiones a distancia mediante un sistema de alertas, de manera que envía un aviso a aquellos trabajadores que realicen más de cinco conexiones laborales fuera de su horario, advirtiendo de la necesidad de desconectar ${ }^{21}$.

- IBM: deja de controlar los días de vacaciones de los trabajadores, argumentando que así estos pueden organizar libremente su ocio y su trabajo ${ }^{22}$.

- Daimler: la empresa permite a sus trabajadores acogerse a un sistema que elimina los correos electrónicos que se les envían mientras que están de vacaciones, recibiendo los remitentes un mensaje en el que se informa de la ausencia, derivándolos a otras

17 Disponible en: https://www.elperiodico.com/es/economia/20180816/derecho-desconexion-digitaltrabajadores-vacaciones-espana-6969761. Consultado 15/10/2018.

${ }^{18}$ Concretamente, en el artículo 4.8.1 se recoge la obligación de desconectarse de las herramientas de trabajo en remoto, para lo cual el empresario debe incorporar herramientas de monitoreo para garantizar que se respeten los tiempos de descanso obligatorios. Además, se contempla en el artículo 4.8.2 la necesidad de garantizar un equilibrio entre la vida personal y profesional para lo cual las empresas afectadas por el convenio deberán velar para que la carga de trabajo permita a los trabajadores conciliar la vida personal y laboral así como su privacidad.

${ }^{19}$ Disponible en: http://noticias.juridicas.com/actualidad/noticias/11315-la-nueva-regulacion-del-derechoa-la-desconexion-digital-del-trabajador-con-la-empresa/. Consultado 01/08/2018.

${ }^{20}$ Disponible en: https://www.yorokobu.es/desconexion-digital-laboral-francia/. Consultado 01/08/2018.

${ }^{21}$ Disponible en: https://www.nobbot.com/personas/desconexion/. Consultado 01/11/2018.

${ }^{22}$ Disponible en: https://www.nytimes.com/2007/08/31/business/worldbusiness/31ihtibm.4.7338756.html?pagewanted=all. Consultado 14/11/2018. 
personas o bien volviendo a enviar el correo cuando el trabajador se haya incorporado a su puesto ${ }^{23}$.

- Axa: en 2017 el convenio colectivo de la empresa recoge el derecho de los trabajadores a no responder a los mails o mensajes profesionales fuera de su horario de trabajo, salvo causas de fuerza mayor o excepcionales, así como no atender a las llamadas en su teléfono móvil corporativo una vez haya terminado su jornada ${ }^{24}$.

- Acuerdo de homologación de las condiciones sociales y laborales entre la plantilla de Santander, Popular y Pastor: reconoce el derecho de los trabajadores a no responder a emails o mensajes profesionales fuera de sus horarios de trabajo, ni durante los tiempos de descanso, permisos, licencias o vacaciones, salvo causa de fuerza mayor o circunstancias excepcionales ${ }^{25}$.

- Ikea: en 2018 introduce el derecho de los trabajadores a no responder comunicaciones por cualquier canal (correo electrónico, teléfono, whatsapp, redes sociales, etcétera). Esto supone la obligación de los directivos de respetar ese derecho a la desconexión, imposibilitándoles enviar comunicaciones a sus trabajadores fuera del horario laboral ${ }^{26}$.

- LG U+: este operador de telefonía de Corea del Sur prohíbe a los gerentes que envíen mensajes a sus empleados después de las 8pm, bajo riesgo de sanciones disciplinarias ${ }^{27}$.

A la vista de las diferentes modalidades de ejercicio del derecho, observamos que, aunque encontramos algunas que ciertamente pueden resultar efectivas, como la ofrecida por el grupo Volkswagen sobre la desconexión de los servidores de comunicación, o la atención durante las vacaciones por otros trabajadores que introduce la empresa Mercedes-Benz, y mas aún, las prohibiciones directas de Ikea o LG U+, lo cierto es que la gran mayoría no resultan novedosas ni aportan soluciones concretas: así, por ejemplo, las medidas de desconexión que recoge la empresa AXA, y similares, no hacen más que plasmar la diferencia entre tiempo de trabajo y tiempo de descanso, estableciendo incluso excepciones inconcretas que no aportan a su contenido nada nuevo ${ }^{28}$. Otras como Orange interpretan la desconexión como una herramienta para

\footnotetext{
23 Disponible en: https://www.businessinsider.es/desconexion-digital-nuevas-leyes-que-evitan-quetengas-que-responder-correo-tu-jefe-despues-trabajo-290119. Consultado el 01/11/2018.

${ }^{24} \mathrm{BOE} \mathrm{n}^{\circ} 244$, de 10 de octubre de 2017.

${ }^{25}$ Disponible en: https://noticiasbancarias.com/bancos/27/06/2018/banco-santander-pone-en-marcha-unaserie-de-mejoras-para-sus-trabajadores/160991.html. Consultado 01/08/2018

26 Disponible en: https://www.20minutos.es/noticia/3370022/0/ikea-establece-desconexion-digitalprohibe-jefes-contacten-trabajadores-fuera-horario-laboral/.Consultado 01/08/2018.

27 Disponible en: https://www.theguardian.com/world/2016/jun/24/south-korea-mulls-ban-on-bossesmessaging-employees-at-home. Consultado 01/08/2018.

${ }^{28}$ MiÑARro YANINI, M., «La "Carta de derechos digitales" para los trabajadores del Grupo Socialista en el Congreso un análisis crítico ante su renovado interés», RTSS.CEF 424 (2018): p.100. En el mismo
} 
favorecer la concentración de los trabajadores dentro de la jornada laboral, lo que no parece corresponderse con la idea original del derecho pensado para cuando ya no se está en el trabajo. Y en el caso de la empresa Michelin, la medida parece admitir hasta cinco conexiones fuera del horario, lo que resulta contradictorio con la propia necesidad de desconexión. Por su parte, la propuesta por IBM de no controlar los periodos vacacionales parece generar justo el efecto contrario que se pretende conseguir, provocando que los trabajadores consulten sus correos electrónicos y teléfonos móviles incluso durante estos días ${ }^{29}$.

Observamos por tanto en muchos de estos intentos de regulación una actitud timorata que parece querer evitar, en el fondo, atajar el problema, y más bien convertir el derecho a la desconexión digital en una declaración programática para favorecer la imagen de la empresa. Probablemente un análisis reposado en los próximos años sobre estos acuerdos colectivos nos dará un resultado mas certero sobre su aplicación y los beneficios obtenidos.

\subsection{Apuntes jurisprudenciales en materia de descanso}

Los conflictos relativos a los límites entre las facultades de organización y dirección empresariales y la vida personal y el descanso de los trabajadores han tenido su reflejo en la jurisprudencia de los tribunales. En este sentido, el derecho a la desconexión digital, como una manifestación más del derecho al descanso en el siglo XXI, puede interpretarse tomando como referencia algunas de estas sentencias.

En el ámbito de la Unión Europea, la STJUE de 7 de septiembre de 2006, C-484/04, asunto Commission v. United Kindong, vino a establecer que las empresas, además de permitir a los trabajadores disfrutar de los descansos correspondientes, deben adoptar un papel activo de vigilancia, supervisión, seguimiento y control con el fin de que sean utilizados de manera efectiva, adoptando en caso de ser necesario las medidas oportunas. Concretamente en el punto 41 se afirma: "teniendo en cuenta el objetivo esencial de la Directiva 93/104, cuya finalidad es proteger de manera eficaz la seguridad y la salud de los trabajadores, cada trabajador debe disfrutar de periodos de descanso adecuados, que no sólo han de ser efectivos, permitiendo a las personas de que se trata recuperarse del cansancio generado por su trabajo, sino también tener un carácter preventivo que reduzca en la medida de lo posible el riesgo de alteración de la

sentido Molina Navarrete, C., «El tiempo de los derechos en un mundo digital: ¿Existe un nuevo “derecho humano a la desconexión” de los trabajadores fuera de la jornada?», Revista de la Facultad de Derecho de México 269, n. ${ }^{\circ}$ Tomo LXVII (2017)

${ }^{29}$ Gordo Gonzalez, L., «El Derecho del Trabajo 2.0: la necesidad de actualizar el marco de las relaciones laborales a las nuevas tecnologías» p.7. 
seguridad y la salud de los trabajadores que puede representar la acumulación de periodos de trabajo sin el descanso necesario". Ello pone de manifiesto que uno de los aspectos a considerar en la regulación del derecho a la desconexión digital tiene que ver con el deber de prevención de la empresa frente a los riesgos para la salud derivados de la sobreexposición tecnológica, como puede ser el tecno-estrés y la tecno-adicción. A su vez, la empresa tiene un deber de vigilancia para que el trabajador no sobrepase la duración de la jornada, respetándose los descansos y el propio derecho a desconectar. Por su parte, la STJUE de 10 de septiembre de 2015, C-266/14, asunto Tyco ${ }^{30}$ analiza el concepto de "tiempo de trabajo" y recoge la diferencia entre éste y tiempo de descanso, interpretando el artículo 2.1 de la Directiva 2003/88 "en el sentido de que, en circunstancias como las controvertidas en el litigio principal, en las que los trabajadores carecen de centro de trabajo fijo o habitual, el tiempo de desplazamiento que dichos trabajadores dedican a los desplazamientos diarios entre su domicilio y los centros del primer y del último cliente que les asigna su empresario constituye 'tiempo de trabajo', en el sentido de dicha disposición". Así pues, cuando ese tiempo de disponibilidad se dedica a una actividad relacionada con el trabajo su naturaleza es laboral, independientemente del lugar donde se preste.

Centrándonos en el orden estatal, cabe destacar la importante Sentencia del Tribunal Constitucional, en adelante STC, 192/2003 de 27 de octubre que aborda de manera amplia el concepto de descanso vacacional, ligándolo con la dignidad y el libre desarrollo de la personalidad, y no como un mero periodo de recuperación durante el cual el trabajador estaría a merced de los intereses empresariales. "Una concepción del derecho del trabajador a las vacaciones retribuidas como la mantenida en las resoluciones judiciales impugnadas equivale a desconocer la dignidad personal del trabajador, entendida ésta como el derecho de todas las personas a un trato que no contradiga su condición de ser racional igual y libre, capaz de determinar su conducta en relación consigo mismo y su entorno, esto es, la capacidad de "autodeterminación consciente y responsable de la propia vida» (STC 53/1985, de 11 de abril, F. 8), así como el libre desarrollo de su personalidad (artículo $10.1 \mathrm{CE}$ ). Recordemos una vez más que la regla del artículo 10.1 CE, proyectada sobre los derechos individuales, implica que la dignidad ha de permanecer inalterada cualquiera que sea la situación en que la persona se encuentre, constituyendo, en consecuencia, un minimum invulnerable que todo estatuto jurídico debe asegurar, de modo que las limitaciones que se

\footnotetext{
${ }^{30} \mathrm{El}$ caso se plantea a propósito de los trabajadores que carecen de centro de trabajo fijo o habitual y a los que la empresa Tyco no contabilizaba como tiempo de trabajo el empleado en el desplazamiento domicilio-clientes, considerándolo como o tiempo de descanso. Los trabajadores afectados eran informados en su teléfono móvil del trayecto que debían realizar y de los servicios concretos que debían prestar a los clientes unas horas antes de la cita, lo que tenía como consecuencia que los mismos ya no tenían la opción de adaptar su vida privada y su lugar de residencia en función de la cercanía al centro de trabajo, puesto que ese centro varía cada día.
} 
impongan en el disfrute de derechos individuales no conlleven un menosprecio para la estima que, en cuanto ser humano, merece la persona [SSTC 120/1990, de 27 de junio (RTC 1990,120), F. 4, y 57/1994, de 28 de febrero (RTC 1994,57), F. 3 A)]". Como sostiene el Tribunal, "la dignidad personal del trabajador se vería severamente limitada de aceptarse un tan omnímodo control como el que se permite en las sentencias impugnadas sobre la persona y vida privada del trabajador por parte de la empresa para la que presta servicios (...)". La relevancia de esta resolución se debe por tanto al hecho de que configura el derecho al descanso, y por extensión que podríamos aplicar al derecho a la desconexión digital, como un límite infranqueable del poder de dirección, con el objetivo final de garantizar la protección de la dignidad y el libre desarrollo de la personalidad, de manera que toda concepción empresarial que considere el tiempo libre del trabajador como tiempo vinculado al interés productivo de la empresa sería inconstitucional, al reducir a simple factor de producción la persona del trabajador.

También algunos temas relacionados con la desconexión digital han sido abordados por la jurisdicción ordinaria. Así, el control de la jornada ordinaria de trabajo ha sido objeto de controversia acerca de la necesidad o no del mismo. En este sentido, la Sentencia del Tribunal Supremo, en adelante STS, sala cuarta pleno, $n^{\circ}$ 246/2017 de 23 de marzo, Rec. 81/2016 ha considerado que el artículo 35.5 ET no obliga a las empresas a llevar un registro diario de la jornada, sino que sólo establece la obligación de registrar las horas extras realizadas por los trabajadores, aunque esta interpretación, como afirman los tres votos particulares, vacía de contenido la obligación de registrar las horas extraordinarias. El problema se complica más aún cuando hay que controlar las horas trabajadas fuera de la jornada laboral y del centro de trabajo habitual, por ejemplo, las horas de disponibilidad, y que como ha expresado el TJUE son horas de trabajo. Alguna luz arroja la Sentencia del Tribunal Superior de Justicia de Castilla León $n^{\circ}$ 168/2016, sala social sección $1^{\text {a }}$, de 3 de febrero de 2016, Rec. 2229/2015, que aclara las bases del control empresarial en lo relativo a la jornada en un supuesto de teletrabajo. La sentencia condena a la empresa al pago de horas extraordinarias sobre la base de la ausencia de control alguno sobre la jornada. Aunque la demandada argumentó que al tratarse de prestación de servicios con una conexión remota, y desde el domicilio del trabajador, no se había establecido ningún control para no interferir en su intimidad e inviolabilidad del domicilio, alegando además la plena libertad de organización y autonomía del trabajador y que hacía imposible la generación de horas extras, para el Tribunal, ha de ser la propia empresa la que debe establecer las reglas de juego del control sobre el trabajador, de modo que la ausencia de estos controles sobre la jornada actúa en claro perjuicio de ella misma. Otro supuesto interesante se recoge en la STS $n^{\circ}$ 4086/2015, sala cuarta sección $1^{\text {a }}$, de 21 de septiembre de 2015, Rec. 259/2014. El objeto del proceso analiza la validez de una cláusula que se introduce en los contratos 
de trabajo en virtud de la cual el trabajador ha de comunicar a la empresa su número de teléfono o su correo electrónico, así como la variación de dichos datos. El Tribunal determina que dicha cláusula resulta abusiva, aunque no se opone a que los trabajadores, voluntariamente, aporten esos datos. Para el Tribunal Supremo se vulnera el derecho fundamental a la protección de datos de carácter personal puesto que la empresa se vale de su posición para que el trabajador, parte débil del contrato, por miedo a no ser contratado admita la inclusión de dicha cláusula, de donde se deriva la ausencia de un consentimiento libre y voluntario. En esta sentencia del Tribunal Supremo se limita nuevamente el poder de dirección empresarial, ahora frente al derecho a la protección de datos de carácter personal de los trabajadores. También en la Sentencia del Tribunal Superior de Justicia de Cataluña $n^{0} 3613 / 2013$, sala social sección $1^{\text {a }}$, de 23 de mayo, Rec. 6212/2012 se reconoce, aunque no se denomina como tal, el derecho a la desconexión digital fuera de la jornada de trabajo. El caso juzga la obligación de una empresa de ascensores de que los trabajadores porten un dispositivo inclusive fuera de la jornada, ya que tienen que cargarlo en sus domicilios y, además, no se puede desconectar. La sentencia en su FJ décimo tercero afirma que el dispositivo tiene una especial incidencia en la salud de los trabajadores por el estrés que les genera estar pendientes de él, pero también porque incide en su esfera privada personal y familiar, ámbito en el que la empresa no puede tener interferencia alguna. Por último, cabe mencionar la Sentencia de la Audiencia Nacional de 17 de julio de 1997, que determina que es ilegal que la empresa obligue a sus trabajadores a estar siempre localizables, pues con ello se sobrepasan las facultades normales y regulares de la misma en los términos del artículo 20 ET. Declara nulas, por tanto, las instrucciones relativas a la necesidad de mantener una conexión ininterrumpida de los teléfonos móviles con los de la empresa y los de todos sus clientes una vez finalizada la jornada de trabajo, extralimitándose el empleador en sus facultades regulares si obliga a los trabajadores a desarrollar su actividad profesional o a estar pendientes de recibir instrucciones en todo momento, incluso en las horas que no coincidan con la jornada laboral, lo que obligaría a que tuviesen que mantener una atención constante de sus teléfonos móviles en todo momento.

En resumen, las respuestas judiciales en torno a los diferentes conflictos expuestos abundan en la separación entre tiempo de trabajo y descanso, dotando de contenido a la desconexión digital, no tanto como un nuevo derecho de los trabajadores, sino mas bien como un deber o un límite para la empresa, debiendo ésta respetar y salvaguardar ciertos derechos fundamentales que, en las nuevas relaciones laborales dominadas por el uso de la tecnología, se tornan más vulnerables, tales como la intimidad, la protección de datos, o la propia conciliación de la vida personal y laboral. Pero al mismo tiempo se configura también ese mismo deber empresarial en un sentido activo con la obligación 
de velar por la salud de sus trabajadores desde la prevención de nuevos riesgos psicosociales como el tecno-estrés o la tecno-adicción.

\section{Naturaleza y contenido del derecho a la desconexión digital}

La LOPDyGDD recoge en su artículo 88 el derecho a la desconexión digital en el ámbito laboral en los siguientes términos:

"1. Los trabajadores y los empleados públicos tendrán derecho a la desconexión digital a fin de garantizar, fuera del tiempo de trabajo legal o convencionalmente establecido, el respeto de su tiempo de descanso, permisos y vacaciones, así como de su intimidad personal y familiar.

2. Las modalidades de ejercicio de este derecho atenderán a la naturaleza y objeto de la relación laboral, potenciarán el derecho a la conciliación de la actividad laboral y la vida personal y familiar y se sujetarán a lo establecido en la negociación colectiva o, en su defecto, a lo acordado entre la empresa y los representantes de los trabajadores.

3. El empleador, previa audiencia de los representantes de los trabajadores, elaborará una política interna dirigida a trabajadores, incluidos los que ocupen puestos directivos, en la que definirán las modalidades de ejercicio del derecho a la desconexión y las acciones de formación y de sensibilización del personal sobre un uso razonable de las herramientas tecnológicas que evite el riesgo de fatiga informática. En particular, se preservará el derecho a la desconexión digital en los supuestos de realización total o parcial del trabajo a distancia así como en el domicilio del empleado vinculado al uso con fines laborales de herramientas tecnológicas".

A primera vista, la redacción parece estar inspirada abiertamente en el precepto francés. El párrafo primero reconoce de manera imperativa el derecho de los trabajadores a la desconexión digital, con el fin de garantizar el tiempo de descanso, permisos y vacaciones, así como su intimidad personal y familiar. Hasta aquí, nada nuevo parece ofrecer el legislador en cuanto a la garantía de derechos que ya se encuentran reconocidos al máximo nivel normativo, es decir, la Constitución, concretamente en sus artículos 18.1 y 4 y 40.2 .

En el párrafo segundo se establecen algunas pautas a la hora de regular las modalidades de ejercicio del derecho. Para empezar, su regulación deberá atender a la naturaleza y objeto de la relación laboral, lo que parece razonable puesto que los requerimientos de los trabajos pueden ser muy variados en función, entre otras cosas, del grado de responsabilidad, del tipo de trabajo prestado, del lugar, etc. Si el derecho a la 
desconexión está pensado para potenciar la conciliación, un aspecto a tener en cuenta es que éste no debe configurarse de manera rígida, puesto que podría, paradójicamente, cercenarla. Por ello, si la conciliación efectiva pasa por facilitar instrumentos como una cierta flexibilidad o adaptación horaria, no puede aplicarse imperativamente y de modo uniforme un derecho a la desconexión digital para toda la plantilla, ya que, como decimos, se estaría atacando los intereses de algunos trabajadores que lo que demandan es flexibilidad para poder realizar tareas en compatibilidad con sus circunstancias personales y familiares. Por tanto, la regulación que se haga del derecho a la desconexión ha de tomar en cuenta tales circunstancias ${ }^{31}$. Abundando en esta idea, incluso existen sectores en los que se debería difuminar, o abandonar la idea de horario, por lo que la desconexión digital dejaría de tener sentido. Así, por ejemplo, Rimbau ${ }^{32}$ aboga por un aumento del trabajo con más posibilidad de autocontrol y gestión, sobre todo en los sectores intensivos en conocimiento que en España ocuparon a un 33\% de la población activa en 2017, y en los que los trabajadores no realizan únicamente tareas sobre cosas o personas, sino que una gran parte de su trabajo consiste en utilizar sus conocimientos y la información que adquieren de modo constante para generar nuevo conocimiento. "En estos sectores, más que horarios, lo que hay que fijar son objetivos (...). Cuando se da a los trabajadores recursos en forma de autonomía y capacidad de auto-organización, y cuando desaparece la expectativa de que estos estén siempre conectados, dichos problemas desaparecen. Con estos recursos y estas expectativas, los trabajadores sienten que son ellos quienes controlan su nivel de conexión y viven el uso de la tecnología como algo beneficioso que les facilita la conciliación". En todo caso, como sostiene Mella Méndez ${ }^{33}$, la solución debe venir de la mano de la negociación colectiva, donde se podrán establecer excepciones al derecho a la desconexión, aunque siempre con la máxima prudencia, según la naturaleza del sector o de la actividad empresarial, o la responsabilidad, funciones o tareas a desempeñar por el trabajador, y ello con amparo en el artículo 17 de la Directiva 2003/88 que exceptúa en materia de tiempos de descansos mínimos a trabajadores autónomos cuya duración total de la jornada no es medida o predeterminada de antemano o que tienen un control total sobre su propio trabajo, especialmente en el caso de ejecutivos y trabajadores con poderes para tomar decisiones autónomas.

El párrafo segundo continúa expresando que las modalidades de ejercicio potenciarán el derecho a la conciliación de la actividad laboral y la vida personal y familiar. Una

\footnotetext{
31 TASCÓN LÓPEZ, R, «El derecho de desconexión del trabajador (potencialidades en el ordenamiento español) (1)».

${ }^{32}$ RimBAU, E., «¿Desconexión digital? Lo que sobran son horarios», elpais.com, sec. Retina, Consultado 13 de noviembre de 2018, Disponible https://retina.elpais.com/retina/2018/11/12/innovacion/1542015099_434138.html.

${ }^{33}$ Mella MÉNDEZ, L., «Nuevas tecnologías y nuevos retos para la conciliación y la salud de los trabajadores (1)».
} 
redacción similar a la norma francesa ${ }^{34}$ que dispone que la negociación anual sobre igualdad profesional entre las mujeres y los hombres y la calidad de vida en el trabajo deben comprender modalidades de ejercicio del derecho a la desconexión que aseguren la vida personal y familiar. Por tanto, el derecho a la desconexión y las formas en que éste se desarrolle, además de garantizar las condiciones de descanso de los trabajadores, se orienta también a "preservar los derechos de conciliación de la vida personal y familiar en planos paralelos de protección jurídica"35. De ello se desprende un indudable aspecto de libertad o autonomía, es decir, de límite infranqueable frente al poder de dirección de la empresa, razón por la que tal vez habría sido más interesante abordarlo como un deber empresarial en lugar de un derecho de los trabajadores ${ }^{36}$. Creemos, por tanto, que el derecho a la desconexión digital en sus múltiples manifestaciones pasaría a formar parte de los derechos de configuración legal que conforman los denominados "derechos de conciliación de la vida personal, familiar y laboral" del artículo 44 de la Ley Orgánica para la Igualdad Efectiva de Mujeres y Hombres 3/2007, en adelante LOI 3/2007, no en su vertiente prestacional, y que habitualmente se manifiesta en actuaciones relacionadas con el tiempo de trabajo, sino, como decimos, a modo de límite para preservar tanto la vida privada, personal y familiar, como el derecho al descanso de los trabajadores. Todos ellos, a fin de cuentas, son garantía de la efectividad del derecho fundamental a conciliar la vida personal y laboral. En este sentido similar, Molina Navarrete ${ }^{37}$ afirma que este derecho a la desconexión formaría parte del contenido esencial del derecho al respeto de la vida privada del trabajador.

Desde comienzos del nuevo siglo, se ha ido configurando el carácter fundamental del derecho a conciliar la vida personal y laboral en el derecho europeo e internacional, se ha incorporado a la Carta de Derechos Fundamentales de la Unión Europea, y nuestro Tribunal Constitucional ha afirmado sin ambages su dimensión constitucional desde la perspectiva de la prohibición de no discriminación por razón de sexo, así como desde la protección a la familia. Además, otros derechos constitucionales clásicos -intimidad, libertad religiosa e ideológica, formación, trabajo, descanso, protección de la salud...-, pueden verse implicados en la relación laboral cuando entran en juego los dos factores que lo caracterizan: la necesidad concreta de conciliar el trabajo con la vida personal/familiar desde una perspectiva de género, y el factor tiempo, si bien hablamos

\footnotetext{
${ }^{34}$ Artículo55.I.2.o de la Ley 2016-1088 que introduce un nuevo apartado $7^{\circ}$ en el artículo L 2242-8 del Código de Trabajo francés.

${ }^{35}$ AlemÁn PÁEZ, F., «El derecho de desconexión digital», Trabajo y Derecho, Sección Estudios, n. ${ }^{\circ} 30$ (2017).

${ }^{36}$ TALÉNS VISCONTI, E., «La desconexión digital en el ámbito laboral: un deber empresarial y una nueva oportunidad de cambio para la negociación colectiva».

${ }^{37}$ Molina NavarRete, C, «El tiempo de los derechos en un mundo digital: ¿Existe un nuevo "derecho humano a la desconexión" de los trabajadores fuera de la jornada?»
} 
de un derecho de naturaleza compleja que aún se encuentra en proceso de consolidación desde una perspectiva amplia que aúne todos sus aspectos -vida personal y familiar-, y cuya demanda por la ciudadanía exige, en definitiva, la garantía de un trabajo digno que posibilite el libre desarrollo de la personalidad de las personas trabajadoras, mujeres y hombres, en condiciones de igualdad $^{38}$. El derecho a la desconexión digital se configuraría de este modo como parte integrante de este derecho fundamental a conciliar en su condición de límite, en el sentido del deber de toda empresa de no interferir en la vida personal y familiar de los trabajadores.

Seguidamente, las modalidades de ejercicio se remiten a lo establecido en la negociación colectiva. Ello enlazaría a su vez con el propio artículo 91 de la LOPDyGDD que prescribe que "los convenios colectivos podrán establecer garantías adicionales de los derechos y libertades relacionados con el tratamiento de los datos personales de los trabajadores y la salvaguarda de derechos digitales en el ámbito laboral'. En efecto, a priori éste parece ser el marco idóneo por las necesidades específicas de cada sector de actividad. Sin embargo, la ausencia de un mandato u obligación firme a los negociadores -y que hubiese requerido una modificación y ampliación del contenido del artículo 85.1 ET-, resulta una mera declaración de buenas intenciones. En su defecto, se establece que las modalidades del derecho se sujetarán a lo acordado entre la empresa y los representantes de los trabajadores. Ello "constituye un condicionante procedimental que hace dudar de su eficacia, puesto que cabe que no exista representación unitaria en el centro por no alcanzar los 11 trabajadores, situación esta que no es infrecuente en la realidad empresarial española. En consecuencia, este condicionante debilita sus garantías y podría, incluso, convertirlo en 'papel mojado', haciendo de esta una mera declaración sin efectos" ${ }^{39}$. En resumen, parece que, a excepción de algunas claves para interpretar la naturaleza del derecho a la desconexión digital, este segundo apartado carecería de eficacia en cuanto a la obligación legal de su desarrollo tanto a nivel convencional como en el plano empresarial, salvo en el caso de las grandes empresas según hemos visto.

Por último, el párrafo tercero, prácticamente idéntico al redactado en el precepto francés, alude a la obligación de la empresa de elaborar una política interna, previa audiencia con los representantes legales, en la que se definan tanto las modalidades de su ejercicio como las acciones de formación y sensibilización del personal sobre el uso

\footnotetext{
${ }^{38}$ ReChe Tello, N., La constitucionalización del derecho fundamental a conciliar la vida personal y laboral (Granada: Comares, 2018).

${ }^{39}$ MiÑARro Yanini, Margarita, «La "Carta de derechos digitales" para los trabajadores del Grupo Socialista en el Congreso un análisis critico ante su renovado interés». Citando a MOLINA NAVARRETE, C., «El tiempo de los derechos en un mundo digital: ¿Existe un nuevo "derecho humano a la desconexión" de los trabajadores fuera de la jornada?».p. 276
} 
razonable de las herramientas tecnológicas, a fin de evitar el riesgo de fatiga informática, preservando, particularmente, el derecho a la desconexión en los supuestos del trabajo a distancia, así como en el domicilio del empleado vinculado al uso con fines laborales de herramientas tecnológicas. Esta remisión final al teletrabajo, como ámbito necesitado de una regulación específica, pese a su tono imperativo como afirma Miñarro Yanini $^{40}$ "no es más que una declaración programática, puesto que no establece ninguna medida concreta". En consecuencia, "si no existen auténticos poderes de negociación individual, ni los convenios colectivos ni los empleadores harán efectivo este derecho. Por ello debe establecerse un contenido mínimo legal del derecho a la desconexión digital, pues es imprescindible para garantizar su eficacia real, siendo esta una de las cuestiones que debería corregirse en el proceso de tramitación parlamentaria que resta".

En cuanto a la ubicación del derecho a la desconexión digital en el ET, la disposición final decimotercera del proyecto LOPDyGDD introduce un nuevo artículo 20 bis con el contenido siguiente:

"Articulo 20 bis. Derechos de los trabajadores a la intimidad en relación con el entorno digital y a la desconexión.

Los trabajadores tienen derecho a la intimidad en el uso de los dispositivos digitales puestos a su disposición por el empleador, a la desconexión digital y a la intimidad frente al uso de dispositivos de videovigilancia y geolocalización en los términos establecidos en la legislación vigente en materia de protección de datos personales y garantía de los derechos digitales."

En nuestra opinión, no parece acertada su incorporación en un precepto dedicado a la dirección y control de la actividad laboral, habiendo sido quizá mas pertinente su inclusión en la Sección 2a $2^{\mathrm{a}}$, dedicada a los derechos y deberes laborales básicos, por ejemplo, en el artículo 4 ET, y desarrollándose posteriormente algunos elementos para su materialización en la Sección $5^{\text {a }}$ dedicada al tiempo de trabajo, incluyendo quizá un apartado noveno en el artículo 34 ET. Posiblemente su forzado encaje en el artículo 20 se deba al hecho de que aún no se ha reconocido el derecho a conciliar como derecho básico de los trabajadores. A ello cabe añadir que como sostiene Baylos Grau, su errada ubicación en el artículo 20 ET se debe a la consideración por el legislador de "los sistemas tecnológicos como instrumentos de vigilancia y control al servicio del poder de dirección del empresario (...) considerándolo como sujeto determinante en este conflicto tecnológico laboral por lo que se impide que el punto de vista normativo se sitúe en la primacía de los derechos fundamentales del trabajador a su intimidad y a la

\footnotetext{
${ }^{40}$ MiÑARRo YANinI, M., «La "Carta de derechos digitales" para los trabajadores del Grupo Socialista en el Congreso un análisis critico ante su renovado interés».
} 
protección de datos en la valoración del perímetro de licitud dentro del cual se debe contener el poder de control tecnológico del empresario, como debería ser lo correcto" 41 .

Por otra parte, como decíamos, su traslación al ET habría requerido establecer un nuevo contenido en el artículo 85 para precisar "el deber de negociar medidas dirigidas a lograr la efectividad del derecho de desconexión laboral del trabajador una vez acabada su jornada, diseñando los cauces y medidas mediante los cuales la empresa garantizará el derecho efectivo de descanso y la imposibilidad de utilización de los dispositivos y servidores informáticos de la empresa fuera de las horas de trabajo, así como sus justificadas excepciones" ${ }^{42}$. Finalmente, teniendo en cuenta la perspectiva de riesgo para la salud que puede provocar la falta de desconexión digital, también habría sido aconsejable incorporar alguna previsión en materia de riesgos laborales y el deber de vigilancia y prevención que corresponde a la empresa, ya que uno de los objetivos de este derecho es proteger la salud psicosocial de los trabajadores.

Del mismo modo, para los empleados públicos la Disposición final decimocuarta (nueva) añade una letra j) bis en el artículo 14 del Texto Refundido de la Ley del Estatuto Básico del Empleado Público, aprobado por Real Decreto Legislativo 5/2015, de 30 de octubre, en adelante EBEP, que quedará redactada como sigue:

“j) bis A la intimidad en el uso de dispositivos digitales puestos a su disposición y frente al uso de dispositivos de videovigilancia y geolocalización, así como a la desconexión digital en los términos establecidos en la legislación vigente en materia de protección de datos personales y garantía de los derechos digitales."

Mucho más adecuada resulta su ubicación en el artículo 14 EBEP, dedicado a los derechos individuales de los empleados públicos, incluyéndolo, en lógica consonancia, a continuación del apartado j que reconoce la adopción de medidas que favorezcan la conciliación de la vida personal, familiar y laboral.

\section{Conclusiones}

No cabe duda de que el reconocimiento de los derechos digitales de los trabajadores en la nueva LOPDyGGD supone un buen punto de partida en el reforzamiento de nuestra legislación laboral, que hasta el momento no contemplaba garantías específicas para la vida privada en el trabajo en la era digital. Concretamente, el derecho a la desconexión

\footnotetext{
${ }^{41}$ Baylos GraU, A., «Los derechos digitales y la negociación colectiva», Diario La Ley 9331 (2019).

${ }^{42}$ TASCÓN LÓPEZ, R., «El derecho de desconexión del trabajador (potencialidades en el ordenamiento español) (1)».
} 
ha acaparado la atención de buena parte de la doctrina científica, y también de los medios de comunicación, sobre todo desde su incorporación en un texto legal en Francia en 2017, y aprobado en términos muy similares en la LOPDyGGD, prueba de que comienza a preocupar esta cuestión. Sin embargo, podemos avanzar que su reconocimiento legal no deja de ser una mera declaración programática que, per sé, no va a contribuir a mejorar la conciliación de los trabajadores. La poca concreción normativa, así como la ausencia de obligatoriedad en la negociación colectiva para el desarrollo de medidas en este sentido, máxime teniendo en cuenta que nuestro tejido empresarial está formado mayoritariamente por pequeñas y medianas empresas, lo dejan en mero papel mojado. Así, y refiriéndose a las experiencias francesa e italiana, Alemán Páez ya ha avanzado que las regulaciones que abordan "estos asuntos mediante normas de mero reconocimiento, y cuyos códigos difieren su alcance sustantivo a instancias colectivas, no son soluciones equilibradoras de los intereses en juego con la digitalización laboral ni ecuánimes respecto del valor intrínseco de los bienes jurídicos protegibles alrededor suyo" "43. A ello debemos añadir la ausencia en el precepto de imposición de garantías ni sanciones por su incumplimiento. Una vez más, necesitaremos reinterpretar el alcance de este derecho/deber a la luz de las resoluciones judiciales existentes, así como del derecho internacional y de la Unión, y la jurisprudencia de los altos tribunales que ya se han pronunciado sobre algunos de sus aspectos. Tal vez la desconexión digital sea una garantía más para la efectividad del derecho al descanso. En este artículo hemos tratado de descifrar su naturaleza, entendiéndolo como parte del derecho fundamental a la conciliación, desde su componente de libertad o autonomía, es decir, como límite infranqueable frente al poder de dirección empresarial. Pero al mismo tiempo, ese deber empresarial de prevención y vigilancia sobre los riesgos psicosociales que pueden acarrear el uso indiscriminado de las nuevas tecnologías, le confiere también una vertiente prestacional, o de hacer, un papel activo por parte del empleador y que paradójicamente podría colisionar con la propia idea matriz de la desconexión, es decir, el deber de abstenerse de interferir en la privacidad de los trabajadores. Al mismo tiempo se abren interrogantes sobre si en determinados sectores de actividad resultaría necesario reconocer este derecho a la desconexión, en vez de potenciar el derecho de adaptación horaria, además de trabajar por cumplimiento de objetivos en vez de por tiempo. ¿Debe la empresa controlar en toda circunstancia la jornada del trabajador? ¿Se deben incrementar los controles para favorecer la desconexión, o es mejor promover una mayor flexibilidad y capacidad de organización y autonomía del trabajador? Creemos que una cuestión fundamental para favorecer la conciliación consiste en posibilitar la compatibilidad efectiva del trabajo con las necesidades personales y/o familiares, mediante fórmulas adaptación horaria, y ello sin tener que renunciar a todo o parte del salario, lo que a su vez tiene efectos beneficiosos para la igualdad de mujeres y hombres y, en ese sentido, las exigencias

${ }^{43}$ ALEMÁN PÁEZ, F., «El derecho de desconexión digital». 
sobre el control de la jornada, o ciertas medidas de desconexión rígidas, pueden repercutir negativamente. En cuanto a su desarrollo futuro por la negociación colectiva, ésta no debería limitarse a incorporarlo, reproduciendo el precepto legal, sino mas bien realizar con carácter previo un análisis de las necesidades específicas de su sector para encontrar las fórmulas más eficaces. En su defecto, las medidas de desconexión deberán plasmarse en acuerdo entre la empresa con sus trabajadores, donde se regulen y desarrollen las que se consideren más convenientes, así como sus excepciones, teniendo presente que deben ser eficaces, aunque no rígidas, ya que pueden ser contrarias a la propia conciliación que deben potenciar, no obstaculizar.

En definitiva, las dificultades de orden práctico que pueda acarrear la regulación de la desconexión digital no deben apartarnos de la firme consideración de que nos encontramos ante una exigencia ineludible en las relaciones de trabajo. Y es que, en este siglo XXI -y los venideros- tan diferente a aquel en el que se configuró inicialmente el derecho al descanso, es mucho lo que nos jugamos si permitimos que unas herramientas creadas por el ser humano para desarrollar todas sus potencialidades en muy distintos ámbitos terminen constituyendo un renovado instrumento de opresión para la que indudablemente continúa siendo parte más débil de la relación laboral. Algo que ya aventuró el historiador y premio Nobel de la Paz Christian Lous Lange cuando afirmó "la tecnología es un siervo útil, pero un amo peligroso".

\section{Bibliografía}

AlemÁn PÁEZ, A.. «El derecho de desconexión digital». Trabajo y Derecho, Sección Estudios, $\mathrm{n}^{\circ}$ 30, 2017.

Baylos Grau, A.. «Los derechos digitales y la negociación colectiva». Diario La Ley $n^{\circ}$ 9331, 2019.

CASAS BAHAMONDE, M.E. "Anotaciones sobre las obligaciones del Estado de garantizar la vida privada en el trabajo en la era digital». Actum Social n 136, 2018.

Gordo GONZÁLEZ, L.. «E1 Derecho del Trabajo 2.0: la necesidad de actualizar el marco de las relaciones laborales a las nuevas tecnologías». Revista de Información Laboral $\mathrm{n}^{\circ}$ $12,2017$.

MELlA MÉNDEZ, L-. «Nuevas tecnologías y nuevos retos para la conciliación y la salud de los trabajadores (1)». Trabajo y derecho: nueva revista de actualidad y relaciones laborales $\mathrm{n}^{\mathrm{o}} 16,2016$, pp.30-52. 
MiÑARRO YANINI, M. «La "Carta de derechos digitales" para los trabajadores del Grupo Socialista en el Congreso un análisis critico ante su renovado interés». RTSS.CEF $\mathrm{n}^{\circ}$ 424, 2018, pp. 91-111.

Molina NAVARRETE, C. «El tiempo de los derechos en un mundo digital: ¿Existe un nuevo "derecho humano a la desconexión" de los trabajadores fuera de la jornada?» Revista de la Facultad de Derecho de México no 269, Tomo LXVII, 2017.

MORENO GONZALEZ-ALLER, I.. «El derecho de los trabajadores a la desconexión tecnológica». Revista Jurisprudencia El Derecho nº 2, 2018.

RECHE TELLO, N.. La constitucionalización del derecho fundamental a conciliar la vida personal y laboral. Comares, Granada, 2018.

RimbaU, E. «¿Desconexión digital? Lo que sobran son horarios». En elpais.com sec. retina. (Fecha de consulta 13 de noviembre de 2018), Disponible en https://retina.elpais.com/retina/2018/11/12/innovacion/1542015099_434138.html.

Sempere Navarro, A V., y Cano Galán, Y. «La igualdad laboral en la Declaración Universal de Derechos Humanos». Revista Europea de Derechos Fundamentales, $\mathrm{n}^{\circ} 11$, 2008, pp.67-136.

TALÉNS VisCONTI, E. «La desconexión digital en el ámbito laboral: un deber empresarial y una nueva oportunidad de cambio para la negociación colectiva». Revista de Información Laboral, no 4, 2018.

TASCÓN LÓPEZ, R. «El derecho de desconexión del trabajador (potencialidades en el ordenamiento español) (1)». Trabajo y Derecho Sección Estudios, nº 41, 2018.

VALLECILlO G, $\mathrm{M}^{\mathrm{A}} \mathrm{R}$.. «El derecho a la desconexión: "novedad digital” o esnobismo del "viejo" derecho al descanso». RTSS.CEF, n 408, 2017.

VIROLÉS PIÑOL, R. «Nuevas tecnologías aplicadas a las relaciones laborales. Incidencia de las recientes sentencias del Tribunal de Justicia de la Unión Europea y del Tribunal Europeo de Derechos Humanos sobre videovigilancia y uso de medios informáticos». En XV Jornadas Laborales, Zaragoza, 2018. 